\title{
Use of Sediment Quality Guidelines (SQGs) in Dredged Material Management
}

PURPOSE: This technical note describes some major features of the most common methods for calculating sediment quality guidelines (SQGs) (U.S. Environmental Protection Agency 1997). The note also describes features that limit the utility of SQGs in dredged material management. In light of these limitations, this technical note specifies circumstances in dredged material assessments where SQGs may be technically appropriate and helpful, and describes conditions in which SQGs are not technically appropriate, for dredged material management decisionmaking.

BACKGROUND: The environmental quality of sediments has been judged by comparison to chemical concentration values for 30 years or more. The early values were derived primarily on the basis of geochemical considerations, or used approaches derived for sewage discharges that bore little relevance to dredged material assessment. Approximately 25 years ago, efforts began to develop methods for deriving values associated with adverse biological effects as opposed to mere chemical presence (Engler 1980, 1990). All past efforts were applied with little success because the methods did not account for the biogeochemical complexity of the interaction of chemicals and sediments (Wright, Engler, and Miller 1992). Over the past two decades, a number of methods and variations on methods for deriving sediment quality values have been developed. All are attempts to determine sediment contaminant concentration values that differentiate sediments of little concern from those predicted to have adverse biological effects.

In this technical note, all values used to determine sediment contaminant concentrations that differentiate sediments of little concern from those predicted to have adverse biological effects are collectively called "sediment quality guidelines" even though they have different names. The term SQG was selected because it has broad and general meaning and has no regulatory connotation as a "pass/fail" criterion or standard. The term SQG is broad enough to encompass all the methods leading to sediment quality guidelines, criteria, etc., which are discussed below. The various methods for determining sediment contaminant concentration values, to differentiate sediments of little concern from those predicted to have adverse biological effects, are presented.

Some methods have been used to derive values that have been codified in State regulations and used to make regulatory decisions. A technical basis for developing sediment quality criteria has been proposed by the U.S. Environmental Protection Agency (EPA), but has never been carried beyond the proposal stage. These and other methods have received varying degrees of attention from the scientific and regulatory communities and citizen groups. Opinions of the utility of SQGs range from essentially worthless to stand-alone, pass-fail determinants of the environmental acceptability of sediments.

This technical note provides guidance to Corps of Engineers staff on the technical context in which SQGs are to be used in dredged material evaluations. It describes the technical limitations of SQGs, which limit their usefulness to Tier 1 or Tier 2 screening of sediments that pose little concern under 
specific circumstances and to identifying those situations in which higher tier effects-based testing may be used to assess sediment acceptability. These limitations also make SQGs by themselves technically unacceptable for making definitive determinations of adverse impacts of sediment to the aquatic environment. Case-specific direct biological effects testing provides a more comprehensive and technically sound basis for such a determination.

\section{MANAGEMENT OF DREDGED MATERIAL IN AQUATIC ENVIRONMENTS USING SQGs}

\section{Derivation of SQGs Relevant to the Aquatic Environment}

Mechanistic derivation methods. Mechanistic derivation methods are those that calculate SQG values based on theoretical considerations that attempt to relate contaminant concentrations to biological responses in some mechanistic manner. Such methods provide at least a theoretical basis for assuming some cause-and-effect relationship between a contaminant of interest and a biological response.

- Equilibrium partitioning (EqP) sediment guidelines. The EPA used the equilibrium partitioning method (USEPA 1993a) to derive draft freshwater sediment quality criteria to protect benthic organisms for five nonionic organic contaminants. These were proposed for comment in 1993 (USEPA 1993b,c,d,e,f; 1997). The EqP method has been used to derive values for a number of contaminants in addition to the five for which EPA proposed draft criteria. The EqP method relies on predicting the partitioning of nonionic organic contaminants between water and the organic carbon in the sediment. It relies on the EPA Ambient Water Quality Criteria for the Protection of Aquatic Life to gauge the potential chronic effects of the calculated contaminant concentration in pore water. EPA used EqP to predict sediment nonionic organic contaminant concentrations below which biological effects are not expected to occur based on the toxicity of individual chemicals (Di Toro and others 1991; USEPA 1993a, 1997).

- Acid volatile sulfides/simultaneously extracted metals (AVS/SEM). Data indicate that sulfides are an important factor controlling the biological availability and effects of metals in sediments (Ankley and others 1996, Meyer and others 1994). The AVS/SEM is an empirical method proposed to predict whether a sediment has sufficient sulfides to tie up and immobilize the metals. An excess of AVS greatly reduces the bioavailability of the metals, while SEM in excess of the AVS may be biologically active. In laboratory studies, no acute toxicity to any benthic test organism was observed in any sediment that had excess AVS (Di Toro and others 1992, Casas and Crecelius 1994). While AVS/SEM is based on equilibrium partitioning theory, it differs from EqP in that AVS/SEM addresses partitioning of ionic metals between sulfides and water, rather than partitioning of nonionic organics between organic carbon and water.

Co-occurrence derivation methods. Co-occurrence derivation methods are used to calculate SQG values based on contaminant presence in a sediment and a biological response. These methods have no theoretical mechanistic basis linking the particular contaminant and the response. 
They are fundamentally statistical methods that provide no basis for assuming any cause-and-effect relationship between a contaminant of concern and a biological response.

- Apparent effects threshold(AET). The AET was developed for and has been used most extensively in the Puget Sound area (Washington). It is a method of numerically relating sediment toxicity or biological community parameters to sediment contaminant concentrations. AET values can be derived for any chemical and any biological parameter such as toxicity to any species, alterations in the community of benthic organisms, and other parameters that can be measured quantitatively. An AET is the sediment contaminant concentration above which the biological response of concern occurred in all samples in the data set used to derive the values (USEPA 1989).

- Effects range low and effects range medium (ERL/ERM). The ERL/ERM method was originated by Long and Morgan (1990) for correlating sediment chemical concentrations with biological responses. They assembled a large data set consisting mostly of AET values, supplemented with some EqP values, results of spiked sediment bioassays, and other types of data. For each chemical, data were arranged in order of increasing concentration. Concentrations not associated with an effect ("no effect" data) were excluded; the ERL was calculated as the lower 10th percentile of "effects" concentrations and the ERM as the 50th percentile of "effects" concentrations. Long and others (1995) refined the method but did not change the basic conceptual approach.

- Threshold effects level and probable effects level (TEL/PEL). This method for correlating sediment chemical concentrations with biological responses was developed by the Florida Department of Environmental Protection (FDEP 1994). The method is similar to the method for deriving ERL/ERM values, but both "effect" and "no effect" data are used in calculating TEL and PEL values. Essentially, the TEL corresponds to the ERL and the PEL to the ERM, with the TEL and PEL values adjusted upward or downward depending on the overlap of the distributions of the "effects" and "no effects" data for each contaminant.

\section{Limitations of SQGs Relevant to the Aquatic Environment}

Limitations common to all aquatic SQG derivation methods. The limitations listed below are common to all SQGs derived by any of the mechanistic or co-occurrence methods. Limitations specific to particular aquatic SQG derivation methods (mechanistic and co-occurrence) are outlined in the following sections.

- Chemical-specific SQGs do not address chemicals for which values have not been developed. A sediment could be below all chemical-specific values and still pose environmental hazards due to other chemicals for which levels have not been developed. This is true regardless of the number of chemicals for which there are SQGs. SQGs provide no means of evaluating such constituents.

- Chemical-specific SQGs do not address unanticipated chemicals. SQGs are developed on a chemical-by-chemical basis and provide no means for evaluating chemicals that may be present in a sediment unknown to the evaluator, but perhaps of environmental importance. Use of SQGs implies that all chemicals of concern have been identified and 
analyzed in the sediment. If there were no known or suspected sources of a particular chemical and the sediment were not analyzed for this chemical, then any effect of this chemical that might be in the sediment from unrecognized sources would not be evaluated using SQGs.

- Chemical-specific SQGs do not address the interaction of chemicals. All SQG derivation methods proposed to date develop values on a single-chemical basis. No method has been proposed to develop SQGs that identify the potential interactions of two or more chemicals present together in the sediment. Such interactions could be either synergistic (the presence of the second chemical increases the effect of the first chemical) or antagonistic (the presence of the second chemical decreases the effect of the first chemical). Contaminated sediments often contain a variety of metallic and organic contaminants. The potential combinations and permutations of these contaminants are almost infinite, making the ability of SQGs to consider only single contaminants acting in isolation a seriously limiting factor.

- SQGs do not adequately consider the exposure component of environmental risk. At a fundamental level, an environmental risk can exist only if there is (1) an effect due to some stressor(s) and (2) exposure of some receptor or organism to the stressor(s). Some SQG derivation methods (for example, AET, ERL/ERM) ignore exposure completely. Others (EqP, AVS/SEM) involve some components of exposure but do not consider aspects of exposure important even in screening-level evaluations (such as physical and biological conditions at the placement site, characteristics of receptor populations, volume of dredged material, dredging and placement methods, temporal and spatial scale of the operation, etc.). One of the reasons that exceedance of SQGs cannot predict adverse environmental impacts is that SQGs are derived primarily on the basis of effect-related considerations and inadequately address exposure-related considerations.

- SQGs developed for one environment have no relevance for other environments. SQGs developed from aquatic data cannot be used to make decisions about placement of dredged material in nonaquatic environments. Some regulatory agencies consider dredged material that exceeds SQGs to be unacceptable for placement at an aquatic site, and then press for placement of such material at upland sites. In such case, SQGs that have no relationship to upland conditions are essentially being used to determine that a dredged material should be placed at an upland site. As such, SQGs derived for anoxic aquatic sediment environments (AVS) have no utility in aerobic (well-oxidized) sediment or terrestrial environments. This approach greatly exceeds any legitimate use of SQGs, and is never appropriate.

\section{Limitations of mechanistic derivation methods.}

- Equilibrium conditions, upon which both the EqP and AVS/SEM methods depend, rarely occur at dredging sites or aquatic dredged material placement sites. Harbor, estuary, and nearshore systems are typically dynamic, with continuous sediment bioturbation and deposition/resuspension due to tides, wind, navigation traffic, etc. Therefore, an essential condition for the validity of the EqP and AVS/SEM methods does not exist at most dredging-related aquatic sites, because equilibrium conditions do not occur.

- EqP and AVS/SEM methods and values have not been verified under field conditions. There have been no adequate attempts to determine whether either method produces values that accurately predict adverse effects under field conditions. Lacking such 
verification, SQGs derived by either method cannot be relied upon to predict unacceptable adverse effects at aquatic dredged material placement sites.

- AVS/SEM methods have little application to sites where macrofauna live, since they depend on the absence of oxygen. AVS cannot exist in the presence of oxygen, and aquatic macrofaunal organisms can exist only in the presence of oxygen. Even though micro-scale changes in sediment oxidation are common in fine-grained sediment (thin-surface layers, lining of burrows, etc.), animals live only in the presence of oxygen and, therefore, in the absence of AVS. In a recent journal article (Ankley and others 1996), it was concluded that AVS/SEM could not be used to predict sediment toxicity but only the absence of toxicity.

\section{Limitations of co-occurrence derivation methods.}

- All co-occurrence methods fail to demonstrate cause and effect. Lacking a cause-and-effect basis, there is no evidence that a contaminant that exceeds its SQG will be associated with an effect in any sediment except the one used to derive the SQG value. Even in deriving the SQG value, the constituent in question may have been present in a nonbioavailable form and had nothing to do with the effect, which may have been caused by other constituents. SQGs that do not demonstrate cause and effect between the contaminant and biological response are of little value in dredged material management. To manage dredged material responsibly at present and to improve the quality of dredged material in the future, it is essential that management actions address those contaminants with a demonstrated mechanism by which they could cause effects in the particular sediment in question.

- The AET method produces inconsistent results. Becker, Barrick, and Read (1990) evaluated the AET approach for assessing contamination of marine sediments in California and compared AET values calculated using data from Puget Sound, northern California, and southern California, with the following results:

\begin{tabular}{|l|l||}
\hline \multicolumn{2}{|c|}{$\begin{array}{c}\text { Difference Between Northern and } \\
\text { Southern California AET Values } \\
\text { Based on Amphipod Toxicity }\end{array}$} \\
\hline Contaminant & Factor \\
\hline Cadmium & 18 -fold \\
\hline Total PCB & 3 -fold \\
\hline Total DDT & 344 -fold \\
\hline p,p' DDT & 100 -fold \\
\hline p,p' DDE & 2,689 -fold \\
\hline p,p' DDD & 64 -fold \\
\hline Fluorene & 17 -fold \\
\hline Fluoranthene & 12 -fold \\
\hline \hline
\end{tabular}

\begin{tabular}{|l|l|}
\hline \multicolumn{2}{|c|}{$\begin{array}{c}\text { Difference Between Puget Sound } \\
\text { and California AET Values Based } \\
\text { on Toxicity to Mussel Larvae }\end{array}$} \\
\hline Contaminant & Factor \\
\hline Cadmium & 16 -fold \\
\hline Total PCB & 12 -fold \\
\hline Total DDT & 3-fold \\
\hline Low molecular weight PAH & 16 -fold \\
\hline High molecular weight PAH & 10 -fold \\
& \\
\hline & \\
\hline
\end{tabular}

Inconsistencies of this sort over a geographic range as small as northern and southern portions of one state make it doubtful that the AET is truly "the contaminant concentration above 
which significant sediment toxicity would always be expected" (Becker, Barrick, and Read 1990).

- AET values have a high probability of being false. In contaminated sediments it is common for multiple contaminants to co-occur, and for their concentrations to be closely correlated. In such cases, the AET derivation process cannot distinguish the effects of chemical A from those of chemical B. Therefore, the AET value for each chemical reflects the combined effects of both chemicals, resulting in false AET values. This phenomenon has been documented statistically by Alden and Rule (1992), who concluded that "the high probability of establishing false AETs that cannot be detected as false would appear to be insurmountable, especially if the goal were the establishment of defensible chemical-specific sediment quality criteria." Consequently, substantial uncertainty is present in AET values.

- ERL/ERM values and TEL/PEL values were derived from data sets including many AET values, and thus are limited in much the same way as AET values. The calculated values cannot escape the limitations of the data from which they were derived. Therefore, the limitations of the AET method should be expected in ERL/ERM and TEL/PEL values derived largely from AET values.

- ERL/ERM values do not reliably predict effects. Sediment samples in which the ERM is exceeded for one or more contaminants are in the "probable effects range" according to the method (Long and Morgan 1990). Long, Field, and MacDonald (in press) present data from 989 sediment samples from the Atlantic, Gulf, and Pacific coasts for which amphipod toxicity and sediment chemistry data were obtained. Samples that exceeded the ERM for one or more contaminants (that is, effects were probable) were actually toxic in only 55 percent of the cases. O'Connor and others (1998) presented data for 1,508 sediment samples with both amphipod toxicity and sediment chemistry data. At least one ERM was exceeded in 239 samples, but only 38 percent of these were actually toxic to amphipods. O'Connor and others (1998) and Long, Field, and MacDonald (in press) showed that exceeding an ERM predicted amphipod toxicity little better than, and perhaps not as well as, flipping a coin. In the O'Connor and others (1998) data set, only 5 percent of the 481 samples that were below all ERLs were toxic to amphipods. This indicated that not exceeding any ERLs may accurately predict lack of amphipod toxicity. (See Long, Field, and MacDonald, in press.)

- TEL/PEL values do not reliably predict effects. Sediment samples in which the PEL is exceeded for one or more contaminants are in the "probable effects range" according to the method (FDEP 1994). Long, Field, and MacDonald (in press) present data from 989 sediment samples from the Atlantic, Gulf, and Pacific coasts for which amphipod toxicity and sediment chemistry data were obtained. Samples that exceeded the PEL for one or more contaminants (that is, effects were probable) were actually toxic in only 51 percent of the cases. Thus, exceeding a PEL predicted amphipod toxicity no better than flipping a coin.

\section{Appropriate Uses of SQGs in Management of Dredged Material in Aquatic Environments}

In the most general sense, toxicity, bioaccumulation, benthic community alterations, etc., tend to increase as sediment contaminant concentrations increase. However, the threshold and nature of this trend are unique to each sediment and controlled by mechanisms not yet well understood. 
Various SQG methods adequately describe the general trend, but because of the uncertainties and limitations described in the previous section, none can reliably identify individual sediments as biologically adverse. Only case-specific direct effects tests can determine that an individual sediment is biologically adverse. Under very specific circumstances, SQGs may be useful as screening values for early identification of sediments of little environmental concern due to contaminants being screened. SQGs should not be used for any other purposes in dredged material evaluations.

SQGs may be useful as initial screening values in Tier 1 or Tier 2 of dredged material evaluations (Ocean and Inland Testing Manuals-USEPA/USACE 1991, 1998) as a part of the "reason to believe" assessment for the presence of sediment contaminants, if appropriate consideration is given to the uncertainties previously described. All SQG derivation processes discussed in this technical note provide adequate assurance that contaminant concentrations below the SQG values are unlikely to cause unacceptable adverse effects. However, due to the uncertainties that have been discussed, sediments that exceed SQGs cannot be regarded as likely to cause unacceptable adverse effects. They can, because of a "reason to believe" contaminants are present, be used to require effects-based testing described in the higher tiers (USEPA/USACE 1991, 1998).

When potential contaminant effects of a specific sediment are being considered in a dredged material evaluation, the following situations are possible:

No contaminant concentrations exceed SQGs (that is, the lower values in the case of ERL/ERM, TEL/PEL, etc.), and

1a. SQGs exist for all contaminants of concern, and there is no concern about interactive effects of multiple contaminants. (In such cases, the sediment in question is unlikely to cause unacceptable adverse effects, and the sediment may be considered environmentally acceptable without further chemical or toxicological testing.)

or

1b. SQGs do not exist for all contaminants of concern, or there is concern about potential interactive effects of multiple contaminants. (In such cases, SQGs do not provide sufficient basis to determine environmental acceptability, and effects-based evaluation is required to support a decision.)

2. Some contaminant concentration(s) exceed SQGs. Such sediments cannot be regarded as likely to cause effects for the reasons discussed in the "Limitations" section. SQGs do not provide sufficient basis to determine environmental acceptability, and further effects-based evaluation is required to support a decision. SQGs in this case can also be used to guide managers in selecting additional sampling locations for those areas deemed to be contaminated.

The conditions in $1 \mathrm{a}$ and $1 \mathrm{~b}$ are important and should not be taken lightly. SQGs can indicate a sediment of minimal potential contaminant impact only if there is an SQG for every contaminant of concern in the sediment. SQGs do not consider risk due to bioaccumulation or trophic transfer of contaminants of concern. The presence of a single contaminant of concern for which there is no 
SQG rules out the use of SQGs for decisionmaking. Since SQGs do not consider possible interactions of contaminants, SQGs cannot be used for decisionmaking if there is concern about possible interactions of multiple contaminants in a sediment. Appropriate SQGs may or may not exist for all contaminants of concern in a sediment. However, if there are any contaminants in a dredged material, it is very unlikely that there will be no concern about possible contaminant interactions, or only a single contaminant present. In cases where SQGs do not provide an adequate basis for decisionmaking, case-specific effects-based testing is required.

Case-specific effects-based testing has been the technical foundation of dredged material evaluations for two decades. It provides a direct measure of whatever effects are tested for in the unique matrix of the specific sediment under evaluation. It overcomes the limitations of SQGs discussed in this technical note that limit the utility of SQGs for decisionmaking in dredged material evaluations. Case-specific effects-based testing measures the effects of all contaminants and their interactions in the specific sediment being evaluated. Because it is case-specific, only effects-based tests relevant to the proposed placement environment are conducted. Case-specific effects-based testing is performed on the sediment under evaluation; it does not depend on values derived from one sediment to evaluate another sediment. Therefore, it does not require that two sediments be at the same (equilibrium) conditions in order to apply predictive values under the same conditions as they were derived. Because effects are measured directly and have been field validated, there is no doubt that some factor(s) associated with the test sediment caused any effects that are measured. Inconsistent or inaccurate predictions are not an issue because effects are not predicted, but are measured directly in the unique matrix of the specific sediment being evaluated.

\section{MANAGEMENT OF DREDGED MATERIAL IN TERRESTRIAL ENVIRONMENTS USING SQGs}

\section{Derivation of Quality Guidelines Used for Dredged Material Placement in the Terrestrial Environment}

Guidelines for the placement of materials on land may be useful in assessing dredged material placement. These various approaches are discussed below and termed "quality guidelines," as SQGs are related to aquatic placement of dredged material.

USEPA 503 regulations. Commonly known as the Part 503 rule, these regulations (40 CFR Part 503) were published in the Federal Register on February 19, 1993. These guidelines were developed for the application of sewage sludge to agricultural land for crop production. The maximum soil values for metals (arsenic, cadmium, chromium, copper, nickel, and zinc) were established through a risk assessment involving selecting representative pathways by which humans, animals, and plants could become exposed to pollutants of concern that can be present in biosolids (USEPA 1995).

- U.S. Department of Agriculture guidance (USEPA/FDA/USDA 1981). The guidelines were developed from the results of experimental data relating the toxic effects of metals on the growth of various agricultural plants in various media (solution cultures, soil cultures, laboratory, greenhouse, and field tests). These guidelines were developed for plant toxicity 
effects as related to metal concentrations of cadmium, copper, and zinc in the soil. Soil concentrations above the guidance levels were expected to result in plant toxicity and plant death.

- Oak Ridge National Laboratory soil values (Efroymson and others 1997). The values presented were termed toxicological benchmarks for screening contaminants of concern for effects on terrestrial plants in ecological risk assessment. These values were derived from published literature and included both soil and solution experimental data. The methods used for deriving soil benchmarks were based on the Long and Morgan (1990) method for deriving effects range low, ERL. The values were assumed to be conservative. When a benchmark was based on an $\mathrm{LC}_{50}$ or on some other endpoint that includes a 50 percent or greater reduction in survivorship, the value was divided by a factor of 5 . This factor was based on the author's expert judgment that a factor of 5 approximates the ratio $\mathrm{LC}_{50} / \mathrm{EC}_{20}$.

- USACE Decisionmaking Framework. The values presented in this document (Lee and others 1991) attempted to summarize available guidance relating to contaminant levels in soils. Values were obtained from various available guidelines, including those of the USDA (USEPA/FDA/USDA 1981, Chaney 1983) (as described in section 5.1.2 of USEPA 1977, 1979); the U.S. Food and Drug Administration (1987); the World Health Organization (1972); the European Community (1974); and from the Netherlands (Dutch Ministry of Agriculture and Fisheries 1973; van Driel, Smilde, and van Luit 1983); the United Kingdom (Ministry of Agriculture, Fisheries, and Food 1972), and Australia (Australian National Health and Medical Research Council 1980). This guidance gives some perspective on how to manage contaminants in dredged material. The concept was that, if there was concern for contaminants at these levels in soils, there might also be concern for contaminant concentrations at or above these levels in dredged material. This may indicate the need for further evaluation, and testing should be considered. This additional testing should follow that described in the USACE/USEPA (1992) Technical Framework for the management of dredged material.

\section{Limitations of Quality Guidelines Relevant to the Terrestrial Environment}

Limitations common to all methods. Assumptions associated with any quality guidelines tend to have given amounts of uncertainty. Major assumptions that limit the utility of all terrestrial guidelines include the following: the contaminant(s) in the dredged material being evaluated will act exactly the same as that contaminant(s) in the soil material from which the guideline was derived; data collected for contaminant uptake by some plants will be applicable to all plants; and data collected for contaminant uptake by some animals will be applicable to other animals.

- USEPA 503 regulations. The guidelines were developed for metals as they exist in sewage sludges that have undergone certain treatment processes in a sewage treatment plant. The treatment processes could include anaerobic digestion and additions of alum, iron sulfate, etc. The 503 risk assessment evaluations considered the reactivity of the contaminant in a sewage sludge matrix under terrestrial environments similar to agricultural fields. Use of these values in dredged material evaluations implicitly assumes that the form of contaminant, the transformations occurring in the sludge applied to agricultural fields, and the bioavailability of the contaminant to plants and animals are the same in the dredged material as in the treated sewage 
sludge. However, differences may be substantial for certain contaminants, dredged material matrices, and site-specific conditions.

- USDA soil value guidance. Use of these guidelines assumes that similar toxic effects would be expected for contaminants found in dredged material as in agricultural soils and that nonagricultural plants are affected in the same way as agricultural plants. However, there may be substantial differences for certain contaminants and plants, especially since research has overwhelmingly demonstrated differential uptake of metals among various agricultural plants (Davies and Houghton 1983; van Driel, Smilde, and van Luit 1983; Chaney 1990). For example, leafy plants such as lettuce and spinach tend to take up large amounts of cadmium, while grasses take up much less cadmium. In many instances, research has shown differential uptake of metals among different varieties within one plant species (Foy, Weil, and Coradetti 1995; Lee 1972).

- Oak Ridge National Laboratory soil values. The report (Efroymson and others 1997) states that "Because of the diversity of soils, plant species, chemical forms, and test procedures, it is not possible to estimate concentrations that would constitute thresholds for toxic effects on the plant communities at particular sites from published toxicity data." Consequently, the guidelines derived are ultra-conservative. For example, the soil benchmark for zinc was set at $50 \mathrm{mg} / \mathrm{kg}$. The average concentration of zinc in the earth's crust is $78 \mathrm{mg} / \mathrm{kg}$ (Lee, Engler, and Mahloch 1976). This means that the average soil would be higher than the toxicological benchmark and, therefore, would be of concern. For comparison, the maximum acceptable soil concentration of zinc according to the USEPA 503 rule is $2,800 \mathrm{mg} / \mathrm{kg}$. Limitations related to these guidelines are similar to those of the ERL values discussed previously, since similar derivation methods were used for both. Uncertainty in the results from applying these guidelines occurs for several reasons: exclusion of synergistic and antagonistic effects resulting from the interactions between chemicals; use of predominantly domestic plant species, which may not be representative of plant species in general; use of predominantly agricultural soils, which may not be representative of soils in general; and laboratory test conditions that may not be representative of field conditions.

- USACE Decisionmaking Framework. The quality guidelines discussed in this approach are presented to give some perspective to the contaminant levels observed in dredged material. The assumption is that the contaminant in the dredged material may react in a manner similar to the same contaminant in the medium from which the guideline was derived. The uncertainty of this assumption may be substantial. The uncertainty in the values relevant to placement of dredged material on land is dependent on the variability and uncertainty of test results for each of the contaminant pathways evaluated according to the Corps' Decisionmaking Framework (Lee and others 1991) and the USEPA/USACE Technical Framework (1992).

\section{Appropriate Uses of Quality Guidelines in Management of Dredged Material in Terrestrial Environments}

In the most general sense, toxicity, bioaccumulation, plant and animal community alterations, etc., tend to increase as contaminant concentrations in the dredged material increase. However, the threshold and nature of this trend are unique to each dredged material and controlled by biogeochemical mechanisms at the disposal environment that are not well understood. Various 
guideline methods tend to describe the general trend, but because of the uncertainties described in the preceding section, none can reliably identify individual dredged material as resulting in unacceptable adverse effects. Only case-specific effects-based testing can determine that an individual dredged material will result in unacceptable adverse impacts to the environment in which it is placed. Under very specific circumstances, these guidelines may be useful as screening values for early identification of dredged material of little environmental concern due to contaminants. They should not be used for any other purposes in dredged material evaluations.

These guidelines may be useful as initial screening values in Tier 1 or Tier 2 of dredged material evaluations as part of the "reason to believe" assessment of sediment contamination, if appropriate consideration is given to the related uncertainties. All guideline derivation processes discussed in this technical note provide adequate assurance that contaminant concentrations below the guideline values are unlikely to cause unacceptable adverse effects due to that contaminant. However, due to the uncertainties discussed in the preceding section, dredged material that exceeds these guidelines cannot be regarded as likely to cause unacceptable adverse effects. They can, because of a "reason to believe" contaminants are present, be used to require effects-based testing described in the higher tiers.

When potential contaminant effects of a specific dredged material are being considered in a dredged material evaluation, the following situations are possible:

No contaminant concentrations exceed guidelines and

1a. Guidelines exist for all contaminants of concern, and there is no concern about interactive effects of multiple contaminants. (In such cases, the dredged material in question is unlikely to cause unacceptable adverse effects, and the dredged material may be considered environmentally acceptable without further testing.)

or

1b. Guidelines do not exist for all contaminants of concern, or there is concern about potential interactive effects of multiple contaminants. (In such cases, SQGs do not provide sufficient basis to determine environmental acceptability, and effects-based testing is required to support a decision.)

2. Some contaminant concentration(s) exceed these guidelines. Such dredged material cannot be regarded as likely to cause effects for the reasons discussed in the "Limitations" section. These guidelines do not provide sufficient basis to determine environmental acceptability, and further effects-based testing is required to support a decision. As such, these guidelines can be used only to identify the need for further effects-based testing.

(Further interpretation of these cases is similar to that discussed in the section "Limitations of SQGs relevant to the aquatic environment," pages 3-6.)

CONCLUSIONS: SQGs have a place in dredged material assessments. They are useful as initial screening values in Tier 1 or 2 evaluations as part of the "reason to believe" that the material is or is not contaminated. If the SQGs or other available information indicates that there is no "reason to 
believe" contaminants are present, no further chemical or toxicological evaluations at higher tiers would be necessary pursuant to the Ocean and Inland Testing Manuals (USEPA/USACE 1991, 1998). If there is a "reason to believe" the sediments are contaminated, toxicological evaluations at higher tiers would be necessary. Because of their inherent uncertainty as previously described, SQGs cannot be used deterministically in dredged material management decisionmaking.

POINT OF CONTACT: For additional technical information contact one of the authors, Dr. Richard K. Peddicord, president, Dick Peddicord \& Company, Inc., (410) 357-4893, and Dr. C. R. Lee, (601) 634-3585, leec@exl.wes.army.mil, or Dr. Robert M. Engler, Senior Scientist (Environmental), (601) 634-3624. Questions of a policy nature should be directed to Mr. Joseph Wilson, Headquarters, U.S. Army Corps of Engineers (CECW-OD), (202) 761-8846.

\section{REFERENCES}

Alden, R. W., III, and Rule, J. H. (1992). "Uncertainty and sediment quality assessments; II. Effects of correlations between contaminants on the interpretation of apparent effects threshold data," Environmental Toxicology and Chemistry 11, 654-61.

Ankley, G. T., Di Toro, D. M., Hansen, D. J., and Berry, W. J. (1996). “Technical basis and proposal for deriving sediment quality criteria for metals," Environmental Toxicology and Chemistry 15(12), 2056-66.

Australian National Health and Medical Research Council. (1980). “Australian National Health and Medical Research Council standards for metals in food,” NSW Government Printer, Sydney, Australia.

Becker, D. S., Barrick, R. C., and Read, L. B. (1990). "Evaluation of the AET approach for assessing contamination of marine sediments in California," State Water Resources Control Board Report No. 90-3SWQ, Sacramento, CA.

Casas, A. M., and Crecelius, E. A. (1994). "Relationship between acid-volatile sulfide and the toxicity of zinc, lead and copper in marine sediments," Environmental Toxicology and Chemistry 13(3), 529-36.

Chaney, R. L. (1983). "Potential effects of waste constituents on the food chain in land treatment of hazardous wastes," Noyes Data Corporation, Park Ridge, NJ, 152-240.

Chaney, R. L. (1990). “Comparison of plant uptake of metals by Cyperus esculentus and agronomic plants grown on sewage sludge amended soils," Contract Report DACW39-89-0030, U.S. Army Engineer Waterways Experiment Station, Vicksburg, MS.

Davies, B. E., and Houghton, N. J. (1983). "Heavy metal uptake by agronomic crops grown on contaminated soils and Cyperus esculentus grown on oxidized and reduced contaminated soils," Contract Report DAJA37-82C-0195, U.S. Army Research, Development and Acquisition Group, UK.

Di Toro, D. M., Mahoney, J. D., Hansen, D. J., Scott, K. J., Carlson, A. R., and Ankley, G. T. (1992). “Acid volatile sulfide predicts the acute toxicity of cadmium and nickel in sediments, Environmental Science and Technology 26(1), 96-101.

Di Toro, D. M., Zarba, C. S., Hansen, D. J., Berry, W. J., Swartz, R. C., Cowan, C. E., Pavlou, S. P., Allen, H. E., Thomas, N. A., and Paquin, P. R. (1991). "Technical basis for establishing sediment quality criteria for nonionic organic chemicals using equilibrium partitioning," Environmental Toxicology and Chemistry 10, 1541-83.

Dutch Ministry of Agriculture and Fisheries, Committee on Mineral Nutrition. (1973). "Tracing and treating mineral disorders in dairy cattle," Center for Agricultural Publishing and Documentation, Wageningen, Netherlands.

Efroymson, R. A., Will, M. E., Suter, G. W., II, and Wooten, A. C. (1997). “Toxicological benchmarks for screening contaminants of potential concern for effects on terrestrial plants: 1997 revision," U.S. Department of Energy ES/ER/TM-85/R3, Oak Ridge National Laboratory, Oak Ridge, TN.

Engler, R. M. (1980). "Prediction of pollution potential through geochemical and biological procedures: Development of regulation guidelines and criteria for the discharge of dredged and fill material," Contaminants and sediments, R. A. Baker, ed., Ann Arbor Science Publishers, Ann Arbor, MI. 
Engler, R. M. (1990). "Managing dredged materials," Oceanus 33(2), 63-69.

European Community. (1974). "Tot Vastellung van de Maximale Gehalten aan Ongewenste Stoffen en Produckten in Diervoeders," Publ. Blad EEG.17, L38, 31-36.

Florida Department of Environmental Protection. (1994). "Approaches to the assessment of sediment quality in Florida coastal waters; 1: Development and evaluation of sediment quality assessment guidelines," prepared for Office of Water Policy, Tallahassee, FL, by MacDonald Environmental Sciences, Ltd., Ladysmith, British Columbia, Canada.

Foy, C. D., Weil, R. R., and Coradetti, C. A. (1995). "Differential manganese tolerances of cotton geotypes in nutrient solutions," Journal of Plant Nutrition 18(4), 685-706.

Lee, C. R. (1972). "Interrelationships of aluminum and manganese on the potato plant," Agronomy Journal 64, 546-49.

Lee, C. R., Engler, R. M., and Mahloch, J. L. (1976). "Land application of waste materials from dredging, construction, and demolition processes," Land application of waste materials. Soil Conservation Society of America, Ankeny, IA, 165-78.

Lee, C. R.,Tatem, H. E., Brandon, D. L., Kay, S. H., Peddicord, R. K., Palermo, M. R., and Francingues, N. R., Jr. (1991). "General decisionmaking framework for management of dredged material," Miscellaneous Paper D-91-1, U.S. Army Engineer Waterways Experiment Station, Vicksburg, MS.

Long, E. R., and Morgan, L. G. (1990). "The potential for biological effects of sediment-sorbed contaminants tested in the National Status and Trends Program," NOAA Tech. Memo. NOS OMA 52, National Oceanic and Atmospheric Administration, Seattle, WA.

Long, E. R., Field, L. J., and MacDonald, D. D. "Predicting toxicity in marine sediments with numerical sediment quality guidelines," Environmental Toxicology and Chemistry (in press).

Long, E. R., MacDonald, D. D., Smith, S. L., and Calder, F. D. (1995). "Incidence of adverse biological effects within ranges of chemical concentrations in marine and estuarine sediments," Environmental Management 19(1), 81-97.

Meyer, J. S., Davison, W., Sundby, B., Ores, J. T., Lauren, D. J., Forstner, U., Hong, J., and Crosby, D. G. (1994). "Synopsis of discussion session: The effects of variable redox potentials, $\mathrm{pH}$ and light on bioavailability in dynamic water-sediment environments." Bioavailability, physical, chemical and biological interactions; Proceedings of the 13th Pellston Workshop, J. L. Hamelink, P. F. Landrum, H. L. Bergman, and W. H. Benson, eds. Lewis Publishers, Boca Raton, FL, 155-70.

Ministry of Agriculture, Fisheries, and Food, United Kingdom. (1972). "Working party on the monitoring of foodstuffs for heavy metals; Second report: Survey of lead in food," Her Majesty's Stationary Office, London, UK.

O’Connor, T. P., Daskalakis, K. D., Hyland, J. L., Paul, J. F., and Summers, J. K. (1998). “Comparisons of sediment toxicity with predictions based on chemical guidelines," Environmental Toxicology and Chemistry 17(3), 468-71.

U.S. Army Corps of Engineers/U.S. Environmental Protection Agency. (1992). "Evaluating environmental effects of dredged material management alternatives-A technical framework," EPA-842-B-92-008, Washington, DC.

U.S. Environmental Protection Agency. (1977). “Air quality criteria for lead,” USEPA Special Series, EPA 600/ 8-77-017, Washington, DC, 12-31.

(1979). "Criteria for classification of solid waste disposal facilities and practices," Federal Register 44 (179), 153, 438-53, 464.

. (1989). "Evaluation of the apparent effects threshold (AET) approach for assessing sediment quality," USEPA Report No. SAB-EETFC-89-027, Science Advisory Board, Washington, DC.

(1993a). "Technical basis for establishing sediment quality criteria for nonionic organic contaminants for the protection of benthic organisms by using equilibrium partitioning," Draft EPA 822-R-93-011, Office of Science and Technology, Health and Ecological Criteria Division, Washington, DC.

(1993b). "Proposed sediment quality criteria for the protection of benthic organisms: Fluoranthene," EPA 822/R93-012, Office of Science and Technology, Health and Ecological Criteria Division, Washington, DC.

(1993c). "Proposed sediment quality criteria for the protection of benthic organisms: Acenapthene," EPA 822/R93-013, Office of Science and Technology, Health and Ecological Criteria Division, Washington, DC. 
U.S. Environmental Protection Agency. (1993d). "Proposed sediment quality criteria for the protection of benthic organisms: Phenanthrene," EPA 822/R93-014, Office of Science and Technology, Health and Ecological Criteria Division, Washington, DC.

. (1993e). "Proposed sediment quality criteria for the protection of benthic organisms: Dieldrin," EPA 822/R93-015, Office of Science and Technology, Health and Ecological Criteria Division, Washington, DC.

. (1993f). "Proposed sediment quality criteria for the protection of benthic organisms: Endrin," EPA 822/R93-016, Office of Science and Technology, Health and Ecological Criteria Division, Washington, DC.

(1995). “A guide to the biosolids risk assessments for the EPA Part 503 Rule,” EPA 832-B-93-005, Office of Wastewater Management, Washington, DC.

(1997). "The incidence and severity of sediment contamination in surface waters of the United States; 1: National Sediment Quality Survey, Appendix B," EPA 823-D-96-002, Office of Science and Technology, Washington, DC.

U.S. Environmental Protection Agency/Food and Drug Administration/U.S. Department of Agriculture. (1981). "Land application of municipal sewage sludge for the production of fruits and vegetables, A statement of Federal policy and guidance," USEPA Joint Policy Statement SW-905, Washington, DC.

U.S. Environmental Protection Agency/U.S. Army Corps of Engineers. (1991). "Evaluation of dredged material proposed for ocean disposal," EPA-503/8-91/001, Washington, DC.

. (1998). "Evaluation of dredged material proposed for discharge in waters of the U.S.-Testing manual," EPA-823-B-98-004, Washington, DC.

U.S. Food and Drug Administration. (1987). "Action levels for poisonous or deleterious substances in human food and animal feed," Center for Food Safety and Applied Nutrition Guidelines and Compliance Research Branch (HFF-312), Washington, DC.

van Driel, W., Smilde, K. W., and van Luit, B. (1983). "Comparison of the heavy-metal uptake of Cyperus esculentus and of agronomic plants grown on contaminated sediments," Miscellaneous Paper D-83-1, U.S. Army Engineer Waterways Experiment Station, Vicksburg, MS.

World Health Organization. (1972). "Evaluation of certain food additives and the contaminants mercury, lead and cadmium," Technical Report Series 505, 16th Report of Joint FAO/WHO Expert Committee on Food Additives, Geneva, Switzerland (also published as FAO Nutrition Report Series No. 51, Rome, Italy).

Wright, T. D., Engler, R. M., and Miller, J. O. (1992). "Effects-based testing and sediment quality criteria for dredged material," Water quality standards for the 21st Century; Proceedings, third national conference, U.S. Environmental Protection Agency, Las Vegas, NV. 